\title{
Biodiversidade em sistemas agroecológicos no município de Choró, CE, Brasil
}

\author{
Biodiversity in agroecological systems in Choró-CE, Brazil
}

\author{
Maria Valdenira Rodrigues de Almeida ${ }^{\mathrm{I}}$ Teogenes Senna de Oliveira ${ }^{\mathrm{II}}$ \\ Antônio Marcos Esmeraldo Bezerra ${ }^{\text {III }}$
}

\section{RESUMO}

Tendo em vista que a biodiversidade é de fundamental importância para a qualidade do agrossistema, este trabalho teve o objetivo de avaliar componentes da biodiversidade em sistemas agroecológicos conduzidos por agricultores familiares no município de Choró, Ceará (CE). Para tanto, áreas cultivadas foram selecionadas pelo tempo de adoção das técnicas de cultivo em consórcio, bem como áreas de vegetação natural próximas, utilizadas como referência. Nessas áreas foram avaliados a fauna edáfica, a flora do extrato herbáceo e arbóreo, o solo e os coprólitos, amostrados aleatoriamente ou em transectos. A riqueza de grupos e os índices de diversidade de Shannon e equalibilidade de Pielou também foram calculados. Os resultados obtidos permitem concluir que o consórcio favoreceu a diversidade da fauna do solo e da flora comparativamente às áreas de vegetação natural.

Palavras-chave: agroecologia, consórcios, semi-árido, sustentabilidade.

\section{ABSTRACT}

Biodiversity is important for the quality of agroecosystems. This study aims to analyze some components of biodiversity in agroecological systems lead by family farmers in the municipality of Choró, CE. Agricultural areas were selected by the time of adoption of intercropping systems as well as areas under natural vegetation used as reference. The soil fauna, the flora of the herbaceous and tree-shrub extracts, soil samples and coprolites were collected randomly or in transects to be analysed. The richness, and diversity and uniformity index (Shannon and Pielou, respectively) were also calculated. The adopted intercropping systems favour the soil fauna and flora diversity when compared to the natural vegetation areas.
Key words: agroecology, intercropping systems, semiarid, sustainability.

\section{INTRODUÇÃO}

É crescente a preocupação, entre os consumidores, com o ambiente e a qualidade de vida, o que exige, cada vez mais, a adoção de métodos de produção agrícola menos agressivos e socialmente justos. O aumento da produtividade das culturas agrícolas para atender a crescente demanda de alimentos tem impulsionado a intensificação da agricultura pela mecanização, pela irrigação, pela adubação química, pelos agrotóxicos, pelas variedades e pelos híbridos produtivos (ZILLI et al., 2003). Contudo, esse aumento provocou impactos alarmantes no ambiente devido à degradação excessiva dos recursos naturais (GLIESSMAN, 2001). Esses impactos são conseqüência do modelo agrícula altamente industrializante e que tem provocado o surgimento de conceitos mais abrangentes tais como "desenvolvimento com eqüidade" e ecodesenvolvimento (CAPORAL \& COSTABEBER, 2000).

Sob o ponto de vista tecnológico, a agricultura em base ecológica é a escolha mais adequada para a sustentabilidade do meio rural, pois considera o agroecosistema como ser vivo e complexo. Sistemas desenvolvidos em base ecológica melhoram

IEsplar - Centro de Pesquisa e Assessoria. Rua Princesa Isabel, 1968, 60015-061, Fortaleza, CE, Brasil.

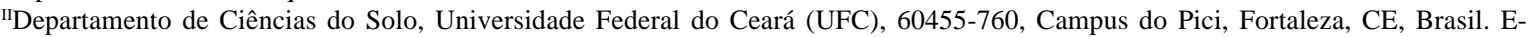
mail: teo@ufc.br. Autor para correspondência.

IIIDepartamento de Fitotecnia, UFC, Campus do Pici, Fortaleza, CE, Brasil. 
a fertilidade do solo, favorecem o aumento da biodiversidade, proporcionam a ciclagem de nutrientes e o fluxo de energia de modo mais eficiente (GLIESSMAN, 2001). Sistemas de cultivo múltiplo, incluindo sistemas consorciados, oferecem aos produtores maior segurança pela diversificação dos cultivos, proporcionando aumento de produtividade e eficiência do aproveitamento do solo (CASANOVA, 2005). O consórcio de culturas é empregado, sobretudo, por pequenos agricultores, pois adequa-se em pequenas áreas e requer pouca mão-de-obra e baixo capital (VIEIRA, 1998). Caracteriza-se pelo crescimento simultâneo de duas ou mais culturas em uma mesma área durante a maior parte dos respectivos períodos vegetativos, possibilitando interação entre elas (KOLMANS \& VÁSQUEZ, 1999; CERETTA, 1986), sendo considerado uma forma de intensificar a produção agrícola mediante o uso eficiente dos fatores de crescimento, espaço e tempo (LEINHNER, 1983). A eficiência e as vantagens do sistema consorciado fundamentam-se na complementaridade entre as culturas envolvidas e estas serão maiores quanto menores forem os efeitos negativos estabelecidos de uma cultura sobre a outra (CERETTA, 1986). A maior densidade de plantas por unidade de área do sistema consorciado em relação ao monocultivo proporciona melhor cobertura do solo, o que reduz a incidência de plantas espontâneas e a erosão (ZAFFARONI, 1987). O consórcio proporciona aumento na renda líquida dos cultivos, pela maior eficiência na utilização de recursos ambientais de água, solos, espaços e redução de riscos de perdas totais. O uso racional de insumos, fertilizantes e agrotóxicos causa também menor impacto sobre o solo e a água (HORWITH, 1985; REZENDE et al., 2005).

Este trabalho teve o objetivo de avaliar componentes da diversidade biológica em áreas conduzidas com consórcios agroecológicos em comparação aos sistemas naturais, no município de Choró, Ceará(CE).

\section{MATERIAL E MÉTODOS}

Foram escolhidas seis áreas situadas no município de Choró-CE (0450’36 “S e 3908’28” W), selecionadas pelo tempo de cultivo consorciado e seu histórico de orientação técnica do Esplar - Centro de Pesquisa e Assessoria (ONG) (Tabela 1). A região é de clima tropical quente semi-árido, de acordo com a classificação de Köppen, com temperaturas variando de 26 a $28^{\circ} \mathrm{C}$ e precipitação pluviométrica média anual de 992mm(IPECE, 2007).
Em cada área, indivíduos da fauna edáfica foram coletados durante sete dias contínuos em três épocas do período seco, novembro e dezembro, e do período úmido, abril e maio, dos anos de 2006 e 2007, respectivamente. Em cada área, foram instaladas 10 armadilhas tipo pit-fall, dispostas em dois transectos lineares, com $10 \mathrm{~cm}$ de diâmetro e $10 \mathrm{~cm}$ de profundidade, enterradas no solo e com abertura ao nível da superfície. Dentro das armadilhas foram colocados $200 \mathrm{~mL}$ da solução álcool etílico hidratado combustível e água (1:1), sendo feita a reposição sempre que necessário. As armadilhas foram mantidas no mesmo local para todas as coletas, sendo inspecionadas e realizadas as coletas dos indivíduos capturados a cada 24 horas. Os indivíduos coletados foram armazenados em álcool etílico a 70\%, classificados e quantificados em base na metodologia descrita por FREITAS et al. (2003). Foi determinada a riqueza da fauna por meio do número de grupos identificados e a diversidade e a uniformidade foram calculadas pelos índices Shannon (H') e Pielou (J'), respectivamente, conforme FREITAS et al. (2003): $\mathrm{H}^{\prime}=-\sum$ pi log pi (1) e que $p i=\frac{n_{i}}{\mathrm{~N}}$; sendo: $n_{I}=$ número de indivíduos do grupo amostrado; $\mathrm{N}$ = número total de indivíduos amostrados; e $\mathrm{S}$ = riqueza das espécies, que é o numero de grupos identificados.

Nos extrato herbáceo e no arbóreo, determinou-se a riqueza por meio do número de grupos identificados. A diversidade e a uniformidade foram estimadas pelos índices Shannon (H') e Pielou (J'), respectivamente, utilizando-se as fórmulas (1) e (2), conforme FREITAS et al. (2003).

O extrato herbáceo foi amostrado nas áreas consorciadas (ACs) e em áreas de vegetação natural (AVNs), em maio de 2007, a partir de cinco amostras aleatórias. Utilizou-se um quadro de $0,5 \mathrm{~m} \times 0,5 \mathrm{~m}$, lançado à medida que se percorria um transecto linear de $10 \mathrm{~m}$. Os indivíduos coletados foram quantificados e identificados no taxum de família. Determinou-se a riqueza por meio do número de grupos identificados, e a diversidade e a uniformidade foram determinadas pelo cálculo dos índices Shannon (H') e Pielou (J'), respectivamente, utilizando-se as fórmulas (1) e (2), conforme FREITAS et. al. (2003).

Os indivíduos do extrato arbóreo das ACs e AVNs com circunferência altura do peito (CAP) maior que $6 \mathrm{~cm}$ foram estudados em outubro de 2007 (RMFC, 2005). Nas AVNs, foram realizadas a identificação e quantificação de espécies em duas parcelas de $10 \mathrm{~m} \mathrm{x}$ 20m. Nas ACs, todos os indivíduos existentes foram identificados e quantificados.

Quatro amostras compostas de solo foram coletadas aleatoriamente em março de 2007. Foram 
Tabela 1 - Localização, características e histórico das áreas amostradas de consórcio (AC) e de vegetação natural (AVN) do município de Choró-CE.

\begin{tabular}{|c|c|c|c|c|}
\hline Agricultor & $\begin{array}{l}\text { Coordenadas } \\
\text { geográficas }\end{array}$ & $\begin{array}{l}\text { Classe de } \\
\text { solo }\end{array}$ & $\begin{array}{l}\text { Área cultivada (ha), culturas, } \\
\text { arranjo e espaçamento }\end{array}$ & Histórico da área de cultivo (AC) e vegetação natural (AVN) \\
\hline $\begin{array}{l}\text { Maria } \\
\text { Liduina da } \\
\text { Silva } \\
\text { (MLS) }\end{array}$ & $\begin{array}{l}\mathrm{S} 04^{\circ} \\
44.841^{\prime} \mathrm{W} \\
039^{\circ} 10.732\end{array}$ & CXve & $\begin{array}{l}\text { 1,1ha, plantados com algodão } \\
\text { ( } 2 \text { fileiras), milho ( } 1 \text { fileira) e } \\
\text { gergelim (1 fileira), com } \\
\text { espaçamento único de } 0,9 \mathrm{~m} x \\
0,8 \mathrm{~m}\end{array}$ & $\begin{array}{l}\text { AC: Área desmatada e queimada em } 1960 \text {, cultivada com } \\
\text { algodão, milho e feijão. Pousio de } 1961 \text { a } 1981 \text {. Desmatada } \\
\text { novamente em 1982, queimada para o cultivo de milho, } \\
\text { feijão, e arroz até 2003, com intervalos de pousio de } 2 \text { anos. } \\
\text { Em } 2005 \text { a área foi preparada solo com arado para o plantio } \\
\text { do consórcio. AVN: Área em pousio desde } 1984 \text {. }\end{array}$ \\
\hline $\begin{array}{l}\text { Francisco } \\
\text { Antonio } \\
\text { Maciel } \\
\text { Dantas* } \\
\text { (FAM) }\end{array}$ & - & - & $\begin{array}{l}\text { 0,5ha, plantados com algodão } \\
\text { ( } 3 \text { fileiras), milho ( } 2 \text { fileiras), } \\
\text { feijão ( } 1 \text { fileira) e gergelim (1 } \\
\text { fileira), com espaçamento } \\
\text { único de } 1 \mathrm{~m} \times 0,8 \mathrm{~m}\end{array}$ & $\begin{array}{l}\text { AC: Área foi desmatada, feito enleiramento, passado } \\
\text { cultivador no ano } 2004 \text { quando adotou a proposta de plantio } \\
\text { agroecológico, plantou na mesma área durante } 3 \text { anos. AVN: } \\
\text { Área em pousio desde } 1999\end{array}$ \\
\hline $\begin{array}{l}\text { João } \\
\text { Alberto } \\
\text { Pinheiro } \\
\text { (JAP) }\end{array}$ & $\begin{array}{l}\mathrm{S} 04^{\circ} \\
43^{\prime} 11.7^{\prime \prime} \\
\text { W039'10’46 } \\
8^{\prime \prime}\end{array}$ & TXo & $\begin{array}{l}\text { 0,7ha, plantados com algodão } \\
\text { (4 fileiras), milho ( } 2 \text { fileira) e } \\
\text { feijão (2 fileiras), com } \\
\text { espaçamento único de } 0,8 \mathrm{~m} x \\
0,8 \mathrm{~m}\end{array}$ & $\begin{array}{l}\text { AC: Área desmatada e queimada em } 1985 \text {. Em } 1985 \text { a } 1987 \\
\text { foi cultivada com milho, feijão e algodão. Pousio de } 1988 \text { a } \\
\text { 2002. Desmatada e queimada novamente para o cultivo de } \\
\text { milho e feijão em 2003. Em } 2004 \text { foi implantado o plantio } \\
\text { agroecológico em 2004. AVN: Área em pousio desde } 1987 \text {. }\end{array}$ \\
\hline $\begin{array}{l}\text { João } \text { Félix } \\
\text { de } \text { Sousa } \\
(\text { JFS })\end{array}$ & $\begin{array}{l}\mathrm{S} 04^{\circ} \\
43^{\prime} 09.8^{\prime \prime} \\
\text { W } 039^{\circ} \\
11^{\prime} 48.8^{\prime \prime}\end{array}$ & $\begin{array}{l}\text { PVAe } \\
\text { PAe }\end{array}$ & $\begin{array}{l}\text { 0,9ha, plantados com algodão } \\
\text { ( } 2 \text { fileiras), milho ( } 2 \text { fileiras) e } \\
\text { feijão (1 fileira) e gergelim (1 } \\
\text { fileira), com espaçamento } \\
\text { único de } 1 \mathrm{~m} \times 0,9 \mathrm{~m}\end{array}$ & $\begin{array}{l}\text { AC: Área desmatada e queimada em 1992, cultivada com } \\
\text { milho e feijão de } 1993 \text { a } 1995 \text { e pousio de } 1996 \text { a } 2002 \text {. Em } \\
2003 \text { teve início da implantação do sistema agroecológico. } \\
\text { AVN: Vegetação natural somente raleada em } 1990 .\end{array}$ \\
\hline $\begin{array}{l}\text { Julio César } \\
\text { Silva do } \\
\text { Nascimento } \\
(\mathrm{JCN}) *\end{array}$ & - & - & $\begin{array}{l}\text { 0,5ha, plantados com algodão } \\
\text { (4 fileiras), milho (2 fileiras) e } \\
\text { feijão ( } 1 \text { fileira), sendo os } \\
\text { espaçamentos do algodão e } \\
\text { do milho e feijão, } \\
\text { respectivamente, de } 1 \mathrm{~m} \text { x } \\
0,5 \mathrm{~m} \text { e } 1 \mathrm{~m} \times 1 \mathrm{~m}\end{array}$ & $\begin{array}{l}\text { AC: Área em pousio desde } 1993 \text { foi desmatada, feito } \\
\text { enleiramento, passado cultivador, em seguida plantada as } \\
\text { culturas em } 2006 \text { quando adotou o plantio agroecológico. } \\
\text { AVN: Área em pousio desde } 1991\end{array}$ \\
\hline $\begin{array}{l}\text { Antonio } \\
\text { Alberto } \\
\text { Benício de } \\
\text { Melo } \\
\text { (AAB) }\end{array}$ & $\begin{array}{l}\mathrm{S} 04^{\circ} \\
40^{\prime} \cdot 20.2^{\prime} \\
\mathrm{W} 039^{\circ} \\
15^{\prime} 30.8^{\prime}\end{array}$ & RYq & $\begin{array}{l}\text { 1,0ha, plantados com algodão } \\
\text { (4 fileiras), milho ( } 1 \text { fileira), } \\
\text { feijão e milho alternados na } \\
\text { mesma fileira ( } 1 \text { fileira), com } \\
\text { espaçamentos de } 1,2 \mathrm{~m} \times 1,1 \mathrm{~m} \\
\text { para o algodão e o milho e } \\
\text { feijão com } 1,1 \mathrm{~m} \times 0,5 \mathrm{~m}\end{array}$ & $\begin{array}{l}\text { AC: Área desmatada e queimada em } 1980 \text { e cultivada com } \\
\text { carnaúba de } 1981 \text { a } 1987 \text {. Área novamente desmatada, } \\
\text { queimada e cultivada com arado para o cultivo de milho e } \\
\text { feijão de } 1988 \text { a } 1994 \text {. Pousio de } 1994 \text { a } 1996 \text { e cultivada } \\
\text { posteriormente com algodão, milho e feijão de } 1996 \text { a } 2002 . \\
\text { Início da implantação do sistema agroecológico em } 2003 . \\
\text { AVN: Área em pousio desde } 1988 \text {. }\end{array}$ \\
\hline
\end{tabular}

* Agricultores que participaram apenas na coleta de dados em 2006; CXve- Cambissolo Háplico Ta eutrófico; TXo- Luvissolo Háplico Órtico planossólico; PVAe- Argissolo Vermelho Amarelo Eutrófico abrúptico; PAe- Argissolo Amarelo Eutrófico planossólico; RYqNeossolo Flúvico Psamítico típico.

segmentadas as áreas de coleta em unidades similares quanto ao relevo e às propriedades de solo de fácil visualização como a cor, a presença de rochas, e cascalhos e o estádio erosivo. As profundidades coletadas foram $0-5 \mathrm{~cm}, 5-10 \mathrm{~cm}$ e $10-30 \mathrm{~cm}$. Coprólitos de minhocas também foram coletados nas AVNs aleatoriamente utilizando-se um quadrado de PVC com área de $0,25 \mathrm{~m}^{2}$, em quatro repetições. As amostras de solo e coprólitos foram secas ao ar, destorroadas, peneiradas e armazenadas para análise. Foram determinados: $\mathrm{pH}$ em água; $\mathrm{P}$ disponível; $\mathrm{K}^{+} \mathrm{Ca}^{2+}, \mathrm{Mg}^{2+}$ e $\mathrm{Al}^{3+}$ trocáveis; acidez portencial $\left(\mathrm{H}^{+}+\mathrm{Al}^{3+}\right)$; soma de bases (SB), capacidade de troca de cátions (CTC), saturação por bases (V) e índice de saturação de sódio (ISNA) (EMBRAPA, 1987). Adicionalmente, determinou-se o $\mathrm{P}$ remanescente e carbono orgânico total (COT), conforme ALVAREZ et al. (2000) e YEOMANS \& BREMNER(1988), respectivamente.

Os resultados da fauna e flora obtidos pelos índices de Shannon e Pielou foram expressos em médias. Para as variáveis de solo e coprólitos, foi realizada a análise de variância. O esquema fatorial com 
níveis de cada fator, agricultores e profundidades teve os coprólitos como testemunhas adicionais, ou seja, 3 x $3+3$. As comparações entre as médias foram feitas por meio de contrastes de interesse considerando a média das profundidades de cada área em relação à testemunha adicional, sendo a significância testada pelo teste $\mathrm{F}$ menor que $10 \%$ de probabilidade.

\section{RESULTADOS E DISCUSSÕES}

A diversidade faunística encontrada nas AVNs e ACs foram semelhantes entre si, com a seguinte composição: a) ordens da classe Insecta: Coleoptera, Diptera, Hemiptera, Hymenoptera, Lepidoptera, Mantodea, Orthoptera; b) ordens da classe Arachnida: Araneae e Scorpiones. Foram encontrados, também, indivíduos das classes Diplopoda e Quilopoda do filo Arthropoda, da classe Gastropoda do filo Molusca e da classe Anphibia do filo Cordata. Os oligoquetos, apesar de presentes, não foram coletados nas armadilhas. As ordens que contribuíram com a maior porcentagem de indivíduos foram: Hymenoptera, Araneae e Coleoptera, destacando-se a família Formicidae. SOUSA (2006) e MOÇO et al. (2005) observaram predomínio da família Formicidae nas situações estudadas. As classes Diplopoda, Quilopoda e Scorpioniones e as ordens Hemíptera e Mantodea apresentaram-se com menos de 5,0\% do total de indivíduos por amostra. Durante o período seco, as áreas de consórcio (ACs) apresentaram um número de indivíduos maior em relação às áreas de vegetação natural (AVNs), enquanto que, no período úmido, foram semelhantes. Esses resultados coincidem com os obtidos por LIMA et al. (2007) e SOUSA (2006) em avaliações semelhantes no semi-árido cearense. Os índices Shannon determinados para as ACs variaram de 0,217 a 0,757, enquanto que nas AVNs foram de 0,233 a 0,736 (Tabela 2). Esses resultados mostraram haver maior amplitude de diversidade nas ACs do que nas áreas de vegetação natural. Os valores são superiores aos encontrados por SOUSA (2006) em sistemas agroecológicos e em vegetação natural no município de Tauá-CE, porém inferiores aos encontrados na região norte fluminense (MOÇO et al., 2005) e em fragmentos florestais da mata atlântica do Rio de Janeiro (BATISTA et al., 2007). Os índices Pielou das ACs, considerando os dois períodos avaliados, variaram entre 0,278 e 0,946, enquanto que nas AVNs variaram entre 0,364 a 0,996 (Tabela 2), sendo superiores aos encontrados por SOUSA (2006) e BATISTA et al. (2007). Portanto, essas áreas de estudo mostraram maior uniformidade em relação às áreas estudadas pelos autores citados, indicando maior equilíbrio na composição dos indivíduos da macrofauna. Ao avaliar a riqueza do grupo da fauna, observa-se que não houve mudanças com relação ao tipo de área natural ou consorciada e nem ao período, seco ou úmido, ou seja, as mesmas ordens e classes foram mantidas.

O número total de indivíduos do extrato herbáceo presente nas áreas consorciadas variou de 190 a 273, divididos em 13 famílias, enquanto que, nas áreas de vegetação natural, foi de 34 a 143 . Predominaram indivíduos da família gramíneas, com proporções que variaram entre 52,77\% e 35,6\%, respectivamente para as ACs e AVNs, sendo seguidos pelas amarantáceas e rubiáceas. Resultados semelhantes foram obtidos por BRIGHENT et al. (2003). O número menor de indivíduos nas AVNs, comparativamente às ACs, pode ser atribuído às condições específicas dessas áreas e que são minimizadas nas AVNs, como, por exemplo a competição por luz, promovida pelo sombreamento das árvores e luz. No entanto, as áreas consorciadas, por estarem num estágio sucessional inferior, podem estar sendo influenciadas pela área de vegetação natural próxima, de acordo com a teoria de biogeografia de ilhas (McARTHUR \& WILSON, 1967). Essa teoria estabelece que a diversidade das espécies num determinado fragmento está associada ao tamanho da área e à distância das fontes de colonização.

A contribuição das áreas naturais fica evidente quando são analisados os valores obtidos para os índices Shannon (Tabela 3). Constataram-se valores entre 0,277 e 0,608 para as ACs, enquanto que nas AVNs os valores variaram de 0,574 a 0,713 , ou seja, há uma maior presença de indivíduos nas ACs em função da contribuição das AVNs. Esses resultados são semelhantes aos encontrados por KUVA et al. (2007) em talhões de canaviais, em Ribeirão Preto, São Paulo (SP). Essa maior diversidade das ACs reflete-se também nos valores do índice de Pielou, pois foram verificadas, respectivamente, variações entre 0,327 e 0,719 para as ACs e de 0,670 a 0,880 para as AVNs (Tabela 3). Apesar da maior diversidade de espécies nas AVNs e de sua potencial contribuição para a maior riqueza das ACs, essas áreas apresentam tendência a uma maior equabilidade. Ecologicamente, as ACs e AVNs são completamente diferentes, pois as ACs apresentam, além da contribuição das AVNs, a manipulação antrópica com fins específicos, propiciando condições ecológicas temporais mais favoráveis, quando comparadas às naturais. Outro fator 
Tabela 2 - Índices de Shannon (H’) e de Pielou (J') e riqueza de grupo (RG) da macrofauna do solo em três coletas realizadas no período seco de 2006 e úmido de 2007, em áreas de vegetação natural (AVN) e consorciados (AC) pertencentes a agricultores/familiares do município de Choró-CE.

\begin{tabular}{|c|c|c|c|c|c|c|c|c|c|c|}
\hline \multicolumn{2}{|c|}{ Área/ Agricultor } & \multicolumn{3}{|c|}{-----------Shannon (H')----------- } & \multicolumn{3}{|c|}{----------Pielou (J')------------ } & \multicolumn{3}{|c|}{------Riqueza de Grupo (RG)----- } \\
\hline & & \multirow[t]{2}{*}{$1^{\mathrm{a}}$} & \multirow[t]{2}{*}{$2^{\underline{a}}$} & $3^{\mathrm{a}}$ & $1^{\underline{a}}$ & $2^{\mathrm{a}}$ & $3^{\mathrm{a}}$ & $1^{\mathrm{a}}$ & $2^{\mathrm{a}}$ & $3^{\mathrm{a}}$ \\
\hline & & & & P------ & o seco c & 06 (nov & o e deze & ------ & --- & ----- \\
\hline & MLS & 0,373 & 0,685 & 0,555 & 0,783 & 0,880 & 0,795 & 3 & 6 & 5 \\
\hline \multirow{4}{*}{ AVN } & FAM & 0,300 & 0,404 & 0,257 & 0,996 & 0,577 & 0,367 & 2 & 5 & 5 \\
\hline & JAP & 0,563 & 0,649 & 0,468 & 0,667 & 0,834 & 0,669 & 7 & 6 & 5 \\
\hline & JFS & 0,401 & 0,469 & 0,240 & 0,573 & 0,671 & 0,399 & 5 & 5 & 4 \\
\hline & JCN & 0,579 & 0,561 & 0,233 & 0,961 & 0,664 & 0,488 & 4 & 7 & 3 \\
\hline \multirow{7}{*}{$\mathrm{AC}$} & $\mathrm{AAB}$ & 0,420 & 0,295 & 0,313 & 0,441 & 0,380 & 0,371 & 9 & 6 & 7 \\
\hline & MLS & 0,536 & 0,752 & 0,504 & 0,891 & 0,890 & 0,836 & 4 & 7 & 4 \\
\hline & FAM & 0,669 & 0,217 & 0,549 & 0,860 & 0,278 & 0,705 & 6 & 6 & 6 \\
\hline & JAP & 0,691 & 0,447 & 0,757 & 0,818 & 0,640 & 0,896 & 7 & 5 & 7 \\
\hline & JFS & 0,392 & 0,631 & 0,457 & 0,504 & 0,811 & 0,654 & 6 & 6 & 5 \\
\hline & $\mathrm{JCN}$ & 0,411 & 0,487 & 0,285 & 0,682 & 0,697 & 0,946 & 4 & 5 & 2 \\
\hline & $\mathrm{AAB}$ & 0,553 & 0,660 & 0,688 & 0,654 & 0,781 & 0,884 & 7 & 7 & 6 \\
\hline & & & & & eríodo ú & de 200 & ril e mai & ----. & 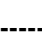 & --- \\
\hline \multirow{4}{*}{ AVN } & MLS & 0,591 & 0,361 & 0,669 & 0,846 & 0,756 & 0,860 & 5 & 3 & 6 \\
\hline & JAP & 0,421 & 0,384 & 0,577 & 0,602 & 0,638 & 0,959 & 5 & 4 & 4 \\
\hline & JFS & 0,464 & 0,744 & 0,736 & 0,549 & 0,880 & 0,848 & 7 & 7 & 8 \\
\hline & $\mathrm{AAB}$ & 0,490 & 0,254 & 0,290 & 0,617 & 0,364 & 0,608 & 7 & 5 & 3 \\
\hline \multirow{4}{*}{$\mathrm{AC}$} & MLS & 0,438 & 0,430 & 0,593 & 0,627 & 0,714 & 0,849 & 5 & 4 & 5 \\
\hline & JAP & 0,479 & 0,438 & 0,622 & 0,615 & 0,519 & 0,889 & 6 & 7 & 5 \\
\hline & JFS & 0,338 & 0,543 & 0,669 & 0,483 & 0,601 & 0,792 & 5 & 8 & 7 \\
\hline & $\mathrm{AAB}$ & 0,752 & 0,437 & 0,612 & 0,890 & 0,726 & 0,725 & 7 & 4 & 7 \\
\hline
\end{tabular}

AC: Área consorciada; AVN: Área de vegetação natural. Riqueza do grupo: número de grupos identificados. Índice Shannon (H’): $\mathrm{H}^{\prime}=-\sum p i \log p i$, em que, $p i=\frac{n_{i}}{\mathrm{~N}}$; sendo: $n_{i}=$ número de indivíduos do grupo amostrado; $\mathrm{N}=$ número total de indivíduos amostrados; e $\mathrm{S}$ = riqueza das espécies em número de grupos identificados. Índice Pielou (J'): $J^{\prime}=\frac{\mathrm{H}^{\prime}}{\log S}$;

Áreas amostradas de MLS - Maria Liduina da Silva; FAM- Francisco Antônio Maciel; JAP - João Alberto Pinheiro; JFS - João Félix de Sousa; AAB - Antonio Alberto Benício.

considerado é o de que todas as AVNs avaliadas estão em pousio há algum tempo, uma vez que foram também utilizadas para fins agrícolas.

O extrato arbóreo das AVNs apresentou 19 espécies em 10 famílias, mostrando menor diversidade do que encontrado por SANTANA et al. (2006), SANTOS et al. (2007) e FRANCELINO et al. (2003) em ambientes semi-áridos de Minas Gerais e do Rio Grande do Norte, respectivamente. A família com maior número de espécies foi a Leguminosa (9), enquanto que em densidade destacaram-se as Euforbiáceas com 259 indivíduos. As leguminosas apresentaram 140 indivíduos, sendo responsáveis por aproximadamente 25\% da população. A espécie Croton sonderianus, pertencente à família das Euforbiáceas, foi responsável por mais de $50 \%$ da população. Essa espécie é nativa da caatinga, que geralmente apresenta grandes populações em áreas perturbadas (OLIVEIRA, 2006).

A maior diversidade do extrato arbóreo das áreas consorciadas pode ser constatada quando comparada com as áreas de vegetação natural, pois foram identificadas 30 espécies e 21 famílias. Esses resultados indicam a possibilidade de implantação de espécies frutíferas nas ACs durante os tratos culturais. Apesar dos altos índices de Shannon de um dos agricultores (JAP), variando de 0,151 a 0,644 para as AVNs e de 0,551 a 1,131 para as ACs, estes não superaram os valores da caatinga obtidos por

Ciência Rural, v.39, n.4, jul, 2009. 
Tabela 3 - Índices de Shannon (H’) e de Pielou (J’) e riqueza de grupo (RG) da vegetação do extrato herbáceo e do arbóreo das áreas consorciadas (AC) e de vegetação natural (AVN), pertencentes a agricultores familiares do município de Choró-CE.

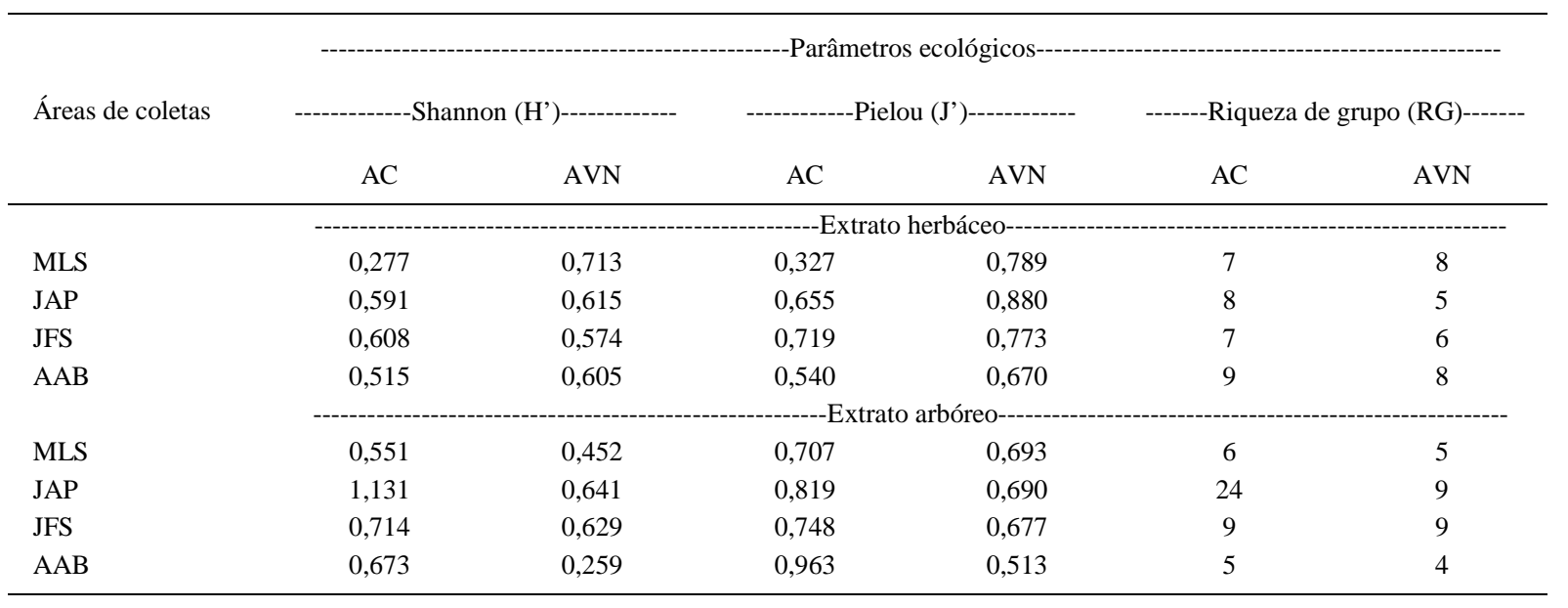

AC: Área consorciada; AVN: Área de vegetação natural. Riqueza: número de grupos identificados. Índice Shannon (H’): $\mathrm{H}^{\prime}=-\sum p i \log p i$, em que $p i=\frac{n_{i}}{\mathrm{~N}}$; sendo: $n_{i}=$ número de indivíduos do grupo amostrado; $\mathrm{N}=$ número total de indivíduos amostrados; e $\mathrm{S}=$ riqueza das espécies em número de grupos identificados. Índice Pielou (J'): $J^{\prime}=\frac{\mathrm{H}^{\prime}}{\log S}$;

Áreas amostradas de MLS - Maria Liduina da Silva; FAM: Francisco Antônio Maciel; JAP - João Alberto Pinheiro; JFS - João Félix de Sousa; AAB - Antonio Alberto Benício.

SANTANA et al. (2006) e OLIVEIRA (2006), respectivamente, dos Estados da Paraíba e do Rio Grande do Norte. O índice de Pielou variou de 0,523 a 0,713 e 0,551 a 1,131 , respectivamente, para AVNs e ACs (Tabela 3), sendo inferiores aos obtidos por VIEIRA et al. (2007).

Em todas as áreas de vegetação natural estudadas, foi observada a presença abundante de coprólitos de minhocas. A coleta de coprólitos foi realizada no intuito de se avaliar as conseqüências da movimentação da superfície promovida por esses artrópodes, comparando-os com as propriedades químicas de solo. Verificou-se que quase todas as propriedades avaliadas apresentaram diferenças significativas $(\mathrm{P}<0,10)$ quando foram comparadas as médias das três profundidades avaliadas e os coprólitos em um ou outro agricultor, destacando-se principalmente o carbono orgânico, o $\mathrm{N}$ e as bases trocáveis, individualmente, ou, quando expressas por propriedades estimadas em saturação por base (V), CTC total ou efetiva, etc. (Tabela 4). QUADROS et al. (2002) também observaram resultados semelhantes quando estudaram os excrementos das minhocas em plantio de eucalipto. RODRIGUES et al. (2003) comentam que, por ocasião da passagem através do trato digestivo das minhocas, a matéria orgânica e os componentes minerais que lhes servem de alimento ficam sujeitos a enzimas digestivas e a um processo de trituração. Segundo BOUCHÉ (1977), a abundância e a distribuição dos diferentes grupos de minhocas variam em função das condições climáticas, da temperatura e da umidade, das condições biológicas, dos tipos de vegetação e da disponibilidade de alimentos e das influências antrópicas devido à interferência direta ou indireta.

\section{CONCLUSÕES}

As práticas agroecológicas adotadas favorecem a maior diversidade da fauna do solo e da flora comparativamente à vegetação natural.

\section{AGRADECIMENTOS}

Aos agricultores familiares das áreas estudadas, ao Esplar, em especial, a José Rogaciano Siqueira de Oliveira e Sérgio Maciel Pinheiro. A Ana Leônia de Araújo, Renato Teixeira Oliveira, Pollyana da Silva Quemel e José Vagner da Silva, estudantes de graduação e pós-graduação da UFC, pela colaboração nas coletas de dados. Ao Conselho Nacional de Desenvolvimento Científico e Tecnológico (CNPq), pelo financiamento deste trabalho, desenvolvido com parte dos recursos do projeto 506070-2004/8 e pela bolsa de produtividade em pesquisa concedida. 
Tabela 4 - Propriedades químicas e físicas e significância $(P)$ de contrastes entre coprólitos de minhocas e solos, município de Choró-CE, 2007.

\begin{tabular}{|c|c|c|c|c|c|c|c|c|c|c|c|c|c|c|c|}
\hline $\begin{array}{l}\text { Profundidade/ } \\
\text { Coprólitos } \\
\text { (cm) }\end{array}$ & dag $k$ & & $\begin{array}{l}\text { pH em } \\
\text { água }\end{array}$ & $\frac{\mathrm{mg}}{\mathrm{dm}^{-3}}$ & ----- & ------- & ------- & $-----c m$ & $\begin{array}{l}\mathrm{H}^{+}+ \\
\mathrm{Al}^{3+}\end{array}$ & 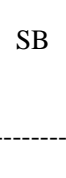 & $\begin{array}{c}\text { CTC } \\
\text { efetiva }\end{array}$ & $\begin{array}{l}\text { CTC } \\
\text { total }\end{array}$ & - & 0----- & P-Rem \\
\hline & \multicolumn{15}{|c|}{ Agricultora Maria Liduína Ferreira da Silva (MLFS) } \\
\hline $0-5$ & 1,99 & 0,03 & 6,37 & 5,37 & 0,30 & 0,02 & 3,94 & 1,38 & 1,80 & 5,65 & 5,65 & 7,45 & 76,11 & 0,47 & 50,50 \\
\hline $5-10$ & 1,15 & 0,02 & 6,22 & 3,35 & 0,21 & 0,03 & 4,25 & 1,40 & 2,15 & 5,90 & 5,90 & 8,05 & 73,35 & 0,63 & 49,27 \\
\hline $10-30$ & 0,77 & 0,02 & 6,24 & 1,55 & 0,11 & 0,07 & 3,73 & 1,46 & 1,88 & 5,37 & 5,37 & 7,24 & 74,16 & 1,26 & 49,55 \\
\hline Média & 1,30 & 0,02 & 6,27 & 3,42 & 0,20 & 0,04 & 3,97 & 1,41 & 1,94 & 5,64 & 5,64 & 7,58 & 74,54 & 0,78 & 49,77 \\
\hline Coprólitos & 2,94 & 0,08 & 6,20 & 7,05 & 0,48 & 0,06 & 3,30 & 1,19 & 3,00 & 5,04 & 5,04 & 8,04 & 63,00 & 1,35 & 51,65 \\
\hline \multirow[t]{2}{*}{$P$} & 0,00 & 0,00 & 0,45 & 0,00 & 0,00 & 0,31 & 0,16 & 0,10 & 0,00 & 0,28 & 0,28 & 0,45 & 0,00 & 0,15 & 0,09 \\
\hline & \multicolumn{15}{|c|}{ Agricultor João Alberto Pinheiro (JAP) } \\
\hline $0-5$ & 1,36 & 0,03 & 6,06 & 5,47 & 0,20 & 0,08 & 4,85 & 1,84 & 2,07 & 6,97 & 6,97 & 9,04 & 77,10 & 1,14 & 52,07 \\
\hline 5-10 & 1,54 & 0,02 & 5,95 & 2,52 & 0,12 & 0,10 & 4,77 & 1,89 & 1,90 & 6,89 & 6,89 & 8,79 & 78,14 & 1,62 & 51,92 \\
\hline $10-30$ & 1,19 & 0,02 & 5,95 & 2,37 & 0,07 & 0,16 & 4,71 & 1,91 & 1,83 & 6,85 & 6,85 & 8,68 & 78,26 & 2,46 & 51,72 \\
\hline Média & 1,36 & 0,02 & 5,98 & 3,45 & 0,13 & 0,11 & 4,77 & 1,88 & 1,93 & 6,90 & 6,90 & 8,83 & 77,83 & 1,74 & 51,90 \\
\hline Cop & 3,26 & 0,07 & 6,73 & 4,87 & 0,35 & 0,03 & 5,60 & 1,57 & 1,70 & 7,56 & 7,56 & 9,26 & 81,62 & 0,51 & 52,87 \\
\hline \multirow[t]{2}{*}{$P$} & 0,00 & 0,00 & 0,00 & 0,10 & 0,00 & 0,00 & 0,08 & 0,02 & 0,32 & 0,24 & 0,24 & 0,49 & 0,21 & 0,00 & 0,37 \\
\hline & \multicolumn{15}{|c|}{ Agricultor João Félix de Sousa (JFS) } \\
\hline $0-5$ & 1,46 & 0,04 & 5,77 & 2,62 & 0,24 & 0,39 & 4,06 & 0,89 & 2,85 & 5,22 & 5,22 & 8,07 & 64,49 & 0,79 & 52,00 \\
\hline $5-10$ & 0,99 & 0,02 & 5,72 & 1,35 & 0,15 & 0,31 & 2,66 & 0,62 & 2,70 & 3,46 & 3,46 & 6,16 & 55,08 & 1,04 & 51,27 \\
\hline $10-30$ & 0,60 & 0,01 & 5,87 & 0,82 & 0,09 & 0,54 & 1,89 & 0,73 & 2,08 & 2,78 & 2,78 & 4,85 & 56,54 & 2,01 & 51,47 \\
\hline Média & 1,01 & 0,02 & 5,78 & 1,59 & 0,16 & 0,41 & 2,87 & 0,74 & 2,54 & 3,82 & 3,82 & 6,36 & 58,70 & 1,58 & 51,58 \\
\hline Cop & 4,21 & 0,08 & 6,48 & 2,97 & 0,32 & 0,03 & 4,48 & 0,85 & 2,35 & 5,69 & 5,69 & 8,04 & 70,70 & 0,53 & 50,92 \\
\hline$P$ & 0,00 & 0,00 & 0,00 & 0,11 & 0,00 & 0,66 & 0,00 & 0,42 & 0,42 & 0,00 & 0,00 & 0,01 & 0,00 & 0,06 & 0,54 \\
\hline
\end{tabular}

CO: Carbono orgânico total; N: nitrogênio orgânico total; pH em água, P: P disponível; K: $\mathrm{K}^{+}$trocável; Na: $\mathrm{Na}^{+}$trocável; $\mathrm{Ca}^{2+}$ : $\mathrm{Ca}^{2+}$ trocável; $\mathrm{Mg}^{2+}: \mathrm{Mg}^{2+}$ trocável; $\mathrm{H}^{+}+\mathrm{Al}^{3+}$ : acidez potencial; SB: Soma de base; V: saturação de bases; ISNA: índice de Saturação de sódio (ISNA); P Rem: P remanescente.

\section{REFERÊNCIAS}

ALVAREZ V. et al. Determinação e uso do fósforo remanescente. Viçosa: Sociedade Brasileira de Ciência do Solo, 2000. 33p. (Boletim Informativo, 25).

BATISTA, I. et al. Avaliação da macrofauna edáfica sob fragmentos florestais em diferentes estádios sucessionais e pasto misto manejado no bioma Mata Atlântica - RJ. In: CONGRESSO BRASILEIRO DE CIÊNCIA DO SOLO, 31., 2007, Gramado RS. Anais...Gramado: Universidade Federal do Rio Grande do Sul, Sociedade Brasileira de Ciência do Solo, 2007. CD- ROM

BOUCHÉ, M.B. Ecologie et paraécologie: peut-on estimer la contribution de la faune aux cycles des éléments biogènes? In: LOHM, U.; PERSSON, T. Soil organisms as components of ecosystems. Proceedings of the $\mathrm{VI}^{\text {th }}$ International Colloquium Soil Zoology, Ecological Bullettin, Stockholm, v.25, p.157-163, 1977.

BRIGHENT, A.M. et al. Cadastramento fitossociológico de plantas daninhas na cultura de girassol. Pesquisa Agropecuária. Brasileira, Brasília, v.38, n.5, p. 651-657, 2003. Disponível em: http://www.scielo.br/scielo.php?script=sci_arttext\&pid=S0100204X2003000500014\&lng=en\&nrm=iso\&tlng=pt. Doi: 10.1590/ S0100-204X2003000500014.
CAPORAL, F.R.; COSTABEBER, J.A. Agroecologia e desenvolvimento rural sustentável: perspectivas para uma nova extensão rural. Agroecologia e Desenvolvimento Rural Sustentável, Porto Alegre, v.1, n.1, p.16-37, 2000.

CASANOVA, A. et al Policultivos, 2005. Capturado em 04 out. 2007. On line. Disponível na internet http/ www.desal.org.mx/IMG/pdf/CASANOVA

REZENDE, B.L.A. et al. Análise econômica de cultivos consorciados de alface americana $\mathrm{x}$ rabanete: um estudo de caso. Horticultura Brasileira, Brasília, v.23, n.3, p.853858, 2005.

CERETTA, C.A. Sistema de cultivo de mandioca em fileiras simples e duplas em monocultivo e consorciada com girassol. 1986. 122f. Dissertação (Mestrado em Fitotecnia) - Universidade Federal do Rio Grande do Sul, Porto Alegre, RS.

EMBRAPA (EMPRESA BRASILEIRA DE PESQUISA AGROPECUÁRIA). Serviço Nacional de Levantamento e Classificação do Solo. Rio de Janeiro, RJ. Manual de métodos de análise do solo. Rio de Janeiro, 1987. 212p.

Ciência Rural, v.39, n.4, jul, 2009. 
FRANCELINO, M.R. et al. Contribuição da caatinga na sustentabilidade de projeto de assentamento no sertão NorteRio-Grandense. Revista Árvore, Viçosa, v.27, n.1, p.79-86, 2003

FREITAS, A.V. et al. Insetos como indicadores ambientais. In: CULLEM JR. L. et al. Métodos de estudos em biologia da conservação e manejo da vida silvestre. Curitiba: UFPR, Fundação Boticário de Proteção á Natureza, 2003. p.125-151.

HORWITH, B. A role for intercropping in modern agriculture. BioScience, Washington, v.35, n.4, p.286-291, 1985.

IPECE - Instituto de Pesquisa e Estratégia Econômica do Ceará. Perfil básico municipal, Choró. Fortaleza: Governo do Estado do Ceará, 2007. 10p.

KOLMANS, E.; VÁSQUEZ, D. Manual de agricultura ecológica: una introduccion a los princípios básicos y su aplicacion. Habana, Cuba: Actaf, 1999. 150p.

KUVA, M.A. et al. Fitossociologia de comunidades de plantas daninhas em agroecossistema cana-crua. Planta Daninha, Viçosa, v.25, n.3, p.501-511, 2007. Disponível em: http://www.scielo.br/ scielo.ph p ? script = s ci_art text \& pid = S $0100-$ $83582007000300009 \& \operatorname{lng}=$ pt\&nrm=iso\&tlng=pt. Doi: 10.1590 S0100-83582007000300009.

LEIHNER, D. Yuca en cultivos asociados. Manejo y evaluación. Cali Colombia: CIAT, 1983. 80p.

LIMA, H.V. et al. Indicadores de qualidade do solo em sistemas de cultivo orgânico e convencional no semi-árido cearense. Revista Brasileira Ciência Solo, Viçosa, v.31, n.5 p.1085-1098, 2007. Disponível em: http:// www.scielo.br/scielo.php? script=sci_arttext\&pid=S0100$06832007000500024 \& \operatorname{lng}=$ en $\& n r m=i s o \& t \operatorname{lng}=p t$. Doi: 10.1590/S0100-06832007000500024.

McARTHUR, R.H.; WILSON, E.D. The theory of island biogeography. Princepton: Princepton University, 1967. 87p.

MOÇO, M.K.S. et al. Caracterização da fauna edáfica em diferentes coberturas vegetais na região norte Fluminense. Revista Brasileira Ciência Solo, Viçosa, v.29, n. 4, p.555-564, 2005. Disponível em: http://www.scielo.br/ scielo.ph p ? s c ript = sci_art text \& pid = S 0100 $06832005000400008 \& \operatorname{lng}=$ en $\& n r m=i s o \& t \operatorname{lng}=p t$. Doi: $10.1590 /$ S0100-06832005000400008.

OLIVEIRA, F.X. Impactos da invasão da algaroba Prosopis juliflora (SW) DC. sobre o componente arbustivoarbóreo da caatinga nas microrregiões do Curimataú e do Seridó nos estados da Paraíba e do Rio Grande do Norte. 2006. 138f. Dissertação (Mestrado em Agronomia) -
Curso de Pós-graduação em Agronomia, Universidade Federal da Paraíba.

QUADROS, R.M.B. et al. Observações sobre as propriedades químicas do solo e de excrementos de minhocas em plantios de Eucalyptus grandis. Boletim Pesquisa Florestal, ColomboParaná v.45, p.29-39, 2002.

RMFC - Comitê Técnico Científico da Rede de Manejo Florestal da Caatinga: protocolo de medições de parcelas permanentes. Recife: Associação e Plantas do Nordeste, 2005. 21p.

RODRIGUES, V.C. et al. Produção de minhocas e composição mineral do Vermicomposto e das fezes procedentes de bubalinos e bovinos. Ciência \& Agrotecnologia,Lavras, v.27, n.6, p.1409-1418, 2003.

SANTANA, J.A.S.; SOUTO, J.S. Diversidade e estrutura fitossociológica da Caatinga na estação ecológica do SeridóRN. Revista de Biologia e Ciências da Terra, Campina Grande v.6, p.232-242, 2006.

SANTOS, R.M. et al. Florística e estrutura de uma floresta estacional decidual, no parque municipal da sapucaia, Montes Claros (MG). Cerne, Lavras, v.13, n.3, p.248-256, 2007.

SOUSA, A.F. Indicadores de sustentabilidade em sistemas agroecológicos por agricultores familiares do semi-árido Cearense. 2006. 93f. Dissertação (Mestrado em solos e nutrição de plantas) - Curso de Pós-graduação em Solos e Nutrição de Plantas, Universidade Federal do Ceará.

VIEIRA, C. Cultivos consorciados. In: VIEIRA, C. et al. (Eds.). Feijão: aspectos gerais e cultura no Estado de Minas Gerais. Viçosa: UFV, 1998. p.523-558.

VIEIRA, T.S. et al. Análise de estrutura e diversidade florística da Reserva Biológica do Jaíba. Revista Brasileira de Biociências, Porto Alegre, v.5, supl.2, p.36-38, 2007.

YEOMANS, J.C.; BREMNER, J.M. A rapid and precise method for routine determination of carbon in soil. Communications Soil Science and Plant Analysis, Philadelphia, v.19, p.14671476, 1988. Disponível em: http://www.informaworld.com/ smpp/content $\sim \mathrm{db}=$ all? content $=10.1080 / 00103628809368027$. Doi: $10.1080 / 00103628809368027$.

ZAFFARONI, E. Yield stability of sole and intercropping systems in the northeast of Brazil. Pesquisa Agropecuária Brasileira, Brasília, v.22, n.4, p.393-399, 1987.

ZILLI, J.E. et al. Diversidade microbiana como indicador de qualidade do solo. Caderno de Ciência \& Tecnologia, v.20, p.319-411, 2003. 